\title{
Retraction Note: Modeling the correlation between Charpy impact energy and chemical composition of functionally graded steels by artificial neural networks
}

\author{
Ali Nazari ${ }^{1}$ \\ Published online: 25 August 2020 \\ (C) Springer-Verlag London Ltd., part of Springer Nature 2020

\section{Retraction Note: \\ Neural Comput \& Applic (2019) 31 (Suppl 2):S707-S721 \\ https://doi.org/10.1007/s00521-012-1010-6}

The Editor-in-Chief has retracted this article [1] because it significantly overlaps with a large number of previously published articles, including [2-6]. Additionally, the article shows evidence of peer review manipulation. The author has not responded to any correspondence regarding this retraction.

\section{References}

1. Nazari A (2019) Modeling the correlation between Charpy impact energy and chemical composition of functionally graded steels by artificial neural networks. Neural Comput Appl 31:707-721. https://doi.org/10.1007/s00521-012-1010-6

This article has been retracted. Please see the retraction notice for more detail: https://doi.org/10.1007/s00521-012$1010-6$

\section{Ali Nazari}

alinazari84@aut.ac.ir

1 Department of Materials Engineering, Saveh Branch, Islamic Azad University, Saveh, Iran
2. Nazari A (2013) Application of artificial neural networks for analytical modeling of Charpy impact energy of functionally graded steels. Neural Comput Appl 22:731-745. https://doi.org/10. 1007/s00521-011-0761-9

3. Nazari A (2013) Analytical modeling of tensile strength of functionally graded steels. Neural Comput Appl 23:787-799. https://doi.org/10.1007/s00521-012-0995-1

4. Bohlooli H, Nazari A, Kaykha MM (2013) RETRACTED: microhardness profile prediction of functionally graded steels by artificial neural networks. Int J Damage Mech 22(1):17-36. https:// doi.org/10.1177/1056789511432653

5. Bohlooli H, Nazari A, Kaykha MM (2012) RETRACTED: analytical modeling of Charpy impact energy of functionally graded steels by ANFIS. Int J Damage Mech 21(6):913-939. https://doi.org/10.1177/1056789511431269

6. Nazari A, Azimzadegan T (2012) Prediction the effects of $\mathrm{ZnO} 2$ nanoparticles on splitting tensile strength and water absorption of high strength concrete. Mater Res 15(3):440-454. https://doi.org/ 10.1590/S1516-14392012005000057

Publisher's Note Springer Nature remains neutral with regard to jurisdictional claims in published maps and institutional affiliations. 